\title{
Time-Domain System Identification of Rigid-Body Multipoint Loads Model
}

\author{
Marcus Vinicius Preisighe Viana* \\ DLR (German Aerospace Center), 38108 Braunschweig, Germany
}

\begin{abstract}
Loads monitoring is of central interest for both aircraft manufacturers and operators. The proper monitoring approach can represent the success or failure of a new aircraft design as well as the economic growth of air carriers. This paper introduces the development of a rigid-body multipoint loads model based on flight test data using System-Identification in time domain. Several strain sensors were calibrated to enable local loads measurements. Direct loads measurements at different positions of the aircraft structure were used to extend the typical set of observation variables, in order to enable the prediction of local aerodynamic loads by this model. For this purpose specific flight test maneuvers covering low frequency inputs at different airspeeds were performed. The test platform is a highperformance sailplane equipped with special flight test instrumentation, in order to allow the modeling of the multipoint loads model at several aircraft load stations. The main contribution of this work is the extension of the conventional System-Identification approach for enabling the simulation of local loads in real time. In this context, the multipoint model structure is outlined and a host of results from the identification of a rigid-body seven-point loads model is presented.
\end{abstract}

\section{Nomenclature}

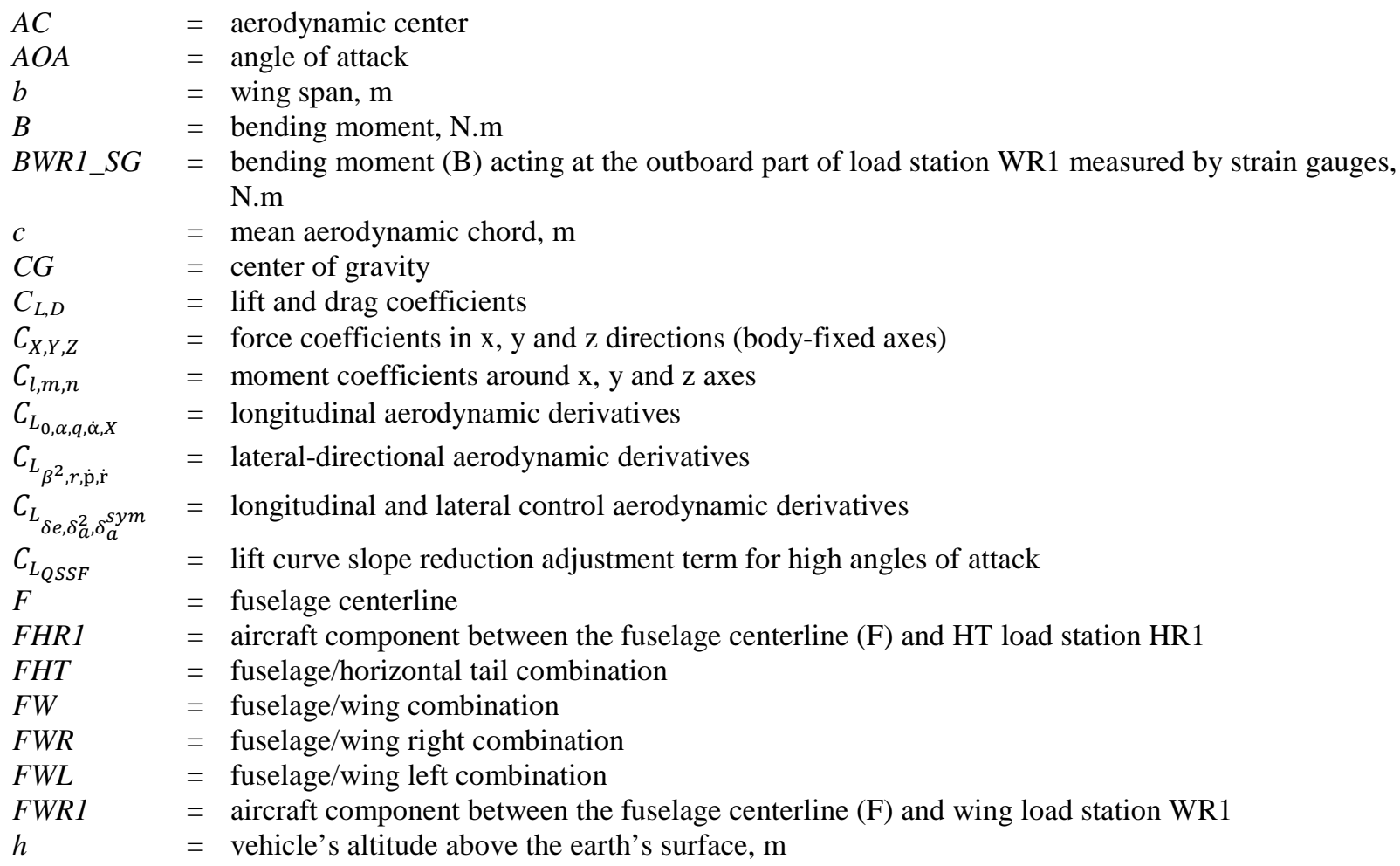

\footnotetext{
* Experimental fixed-wing flight test engineer and $\mathrm{PhD}$ candidate, Institute of Flight Systems, Lilienthalplatz 7, 38108 Braunschweig, Germany, marcus.preisigheviana@dlr.de.
} 


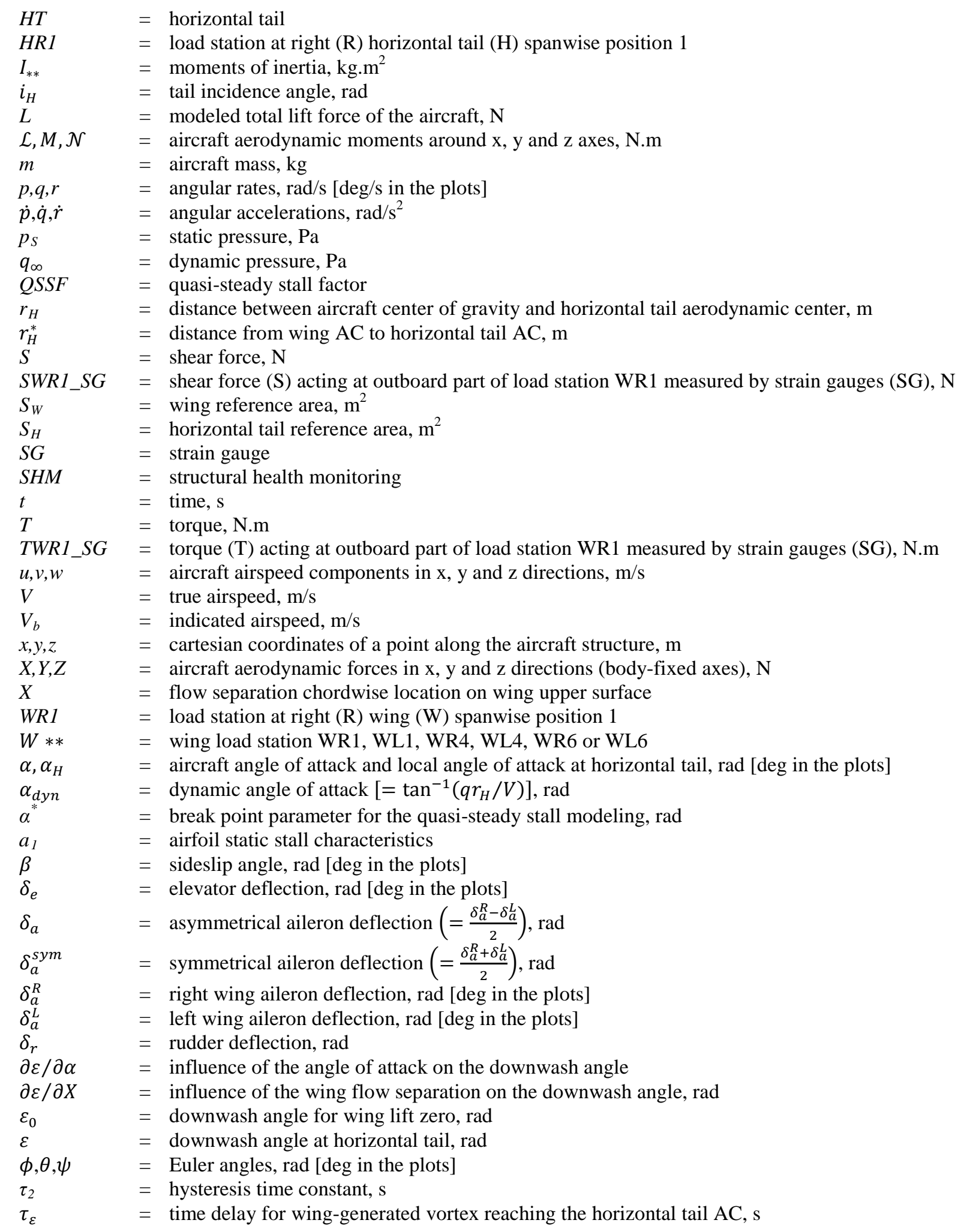




\section{Introduction}

$\mathrm{T}$

HE topic of Structural Health Monitoring (SHM) is present during the entire aircraft lifecycle, affecting the phases of design, certification and operation. In addition to the scientific interests in flight loads modeling, loads monitoring is primarily of importance for air carriers and original equipment manufacturers. This is due to the high costs involved in the process of airframe maintenance that plays an important role in aircraft operation.

The strain sensor calibration for measuring flight loads is an essential step prior to the loads flight test program necessary to meet certification requirements. This program has to validate the calculated design loads and produce reliable loads predictions for the certification load cases ${ }^{1}$. Load equations derived from calibrated strain gauge measurements at certain positions of the aircraft structure are required to enable the validation and update of analytical design loads models, which compose conventional offline SHM systems. However, the real-time direct loads monitoring approach based on load equations can present drawbacks, for instance, due to the requirement of numerous strain sensors that are expected to be reliable and stable during the entire aircraft lifecycle (e.g. 30 years). This cannot be feasible especially considering harsh environments (e.g. operational flights). Therefore, a new approach that addresses the modeling of the aircraft loads can be valuable in contributing to future real-time SHM systems. This constant quest for new SHM systems is due to the requirements for safe continued airworthiness, where proper maintenance programs meeting the means of compliance are needed to be undertaken by the aircraft operators. This means that effective real-time loads monitoring are required to aid air carriers to optimize their maintenance programs and inspection intervals through effective component lifecycle monitoring.

Despite the significant amount of research work $^{2-21}$, there are still gaps in several research areas of loads modeling and SHM. This work considers the problem of developing a rigid-body multipoint loads model, whose loads modeling approach is envisaged to contribute to the development of future real-time SHM systems. For this purpose, local aerodynamic load equations were developed from strain sensor measurements. A rigid-body 7-point lift model for a high-performance sailplane will demonstrate the contribution of this work. The local aerodynamic loads modeling was performed by the use of comprehensive flight-test data including direct structural loads measurements. The conventional global time-domain System-Identification ${ }^{22}$ was extended by the capability of local loads assessment, where local loads measurements are included in the observation equations. The identified multipoint loads model goes a step further of the current state-of-the-art rigid-body modeling and enables the capability of simulating local aerodynamic loads by the exclusive use of flight parameters measured by the standard aircraft sensors. This is quite important especially for cases where direct measurements (monitoring) of local loads data through strain sensors are difficult or infeasible ${ }^{4}$.

Furthermore, the development of the rigid-body loads model is a necessary step to obtain the aeroelastic loads model of a flexible aircraft. This structural flexibility modeling is important because structural dynamics effects play a crucial role on the local loads developed for different aircraft components. These structural effects may reduce the structural life of the aircraft due to high levels of dynamic loads caused for example by atmospheric turbulence.

In the first part of this paper the research methodology is presented, strain sensor load equations and the performed flight tests are addressed. The second part explains the multipoint loads model structure. In this context, the extension of the conventional System-Identification approach by including additional observation variables is explained. Finally, the identification results of the rigid-body multipoint loads model are presented.

\section{Research Approach}

\section{A. Methodology}

The conventional System-Identification uses the aircraft flight data as input in order to model the aircraft aerodynamic loads. However, due to the limited information provided by the standard measured flight data, only the global contributions of the wing/fuselage and horizontal tail are modeled (example in Fig. 1 for lift, pitching and rolling moment coefficients $C_{L, m, l}$ ). The measured observation variables (e.g. angular rates) are compared with the correspondent model predictions and the minimization of the deviation between them allows the estimation of the postulated model parameters.

This approach does not allow the modeling of local aerodynamic loads. The objective of this work is to provide the capability of prediction of local loads. However, this multipoint loads modeling requires the availability of local loads measurements as additional observation variables to provide sufficient information for the identification of the significant number of parameters. Figure 2 depicts the strain sensor calibration steps used to transform 46 strain gauge measurements (i.e. SG1 to SG46) in local structural loads [shear force (S), bending moment (B) and torque (T)] at seven load stations (i.e. WR/L1, WR/L4, WR/L6 and HR1, see Fig. 4) ${ }^{23}$. After suitable computations ${ }^{23,24}$ the 
measured local aerodynamic loads $C_{L, m, l}$ were obtained. These measured local aerodynamic coefficients support the development of a rigid-body seven-point loads model by System-Identification as summarized in Fig. 2.

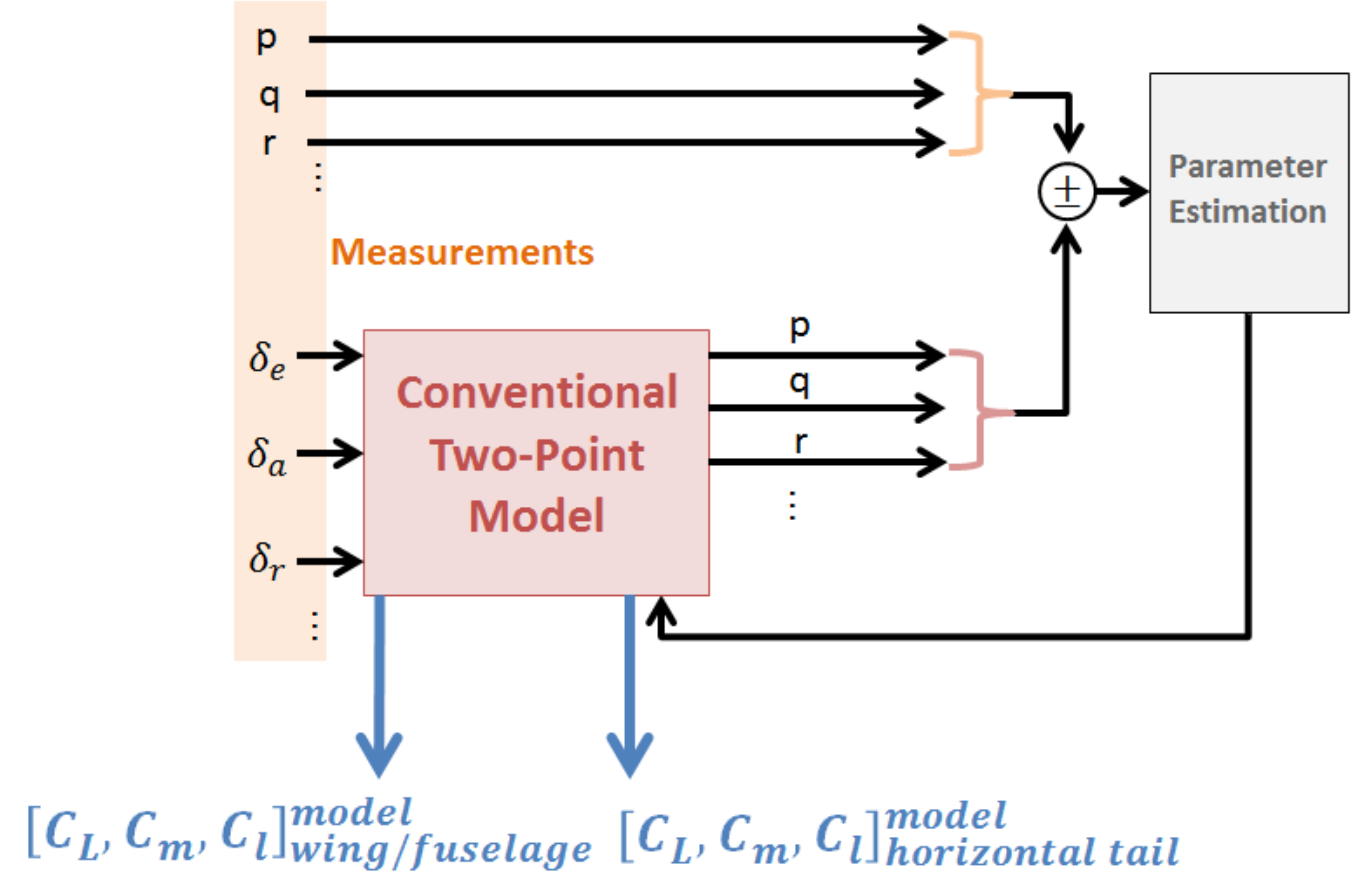

Figure 1. Conventional System-Identification approach of rigid-body global model.

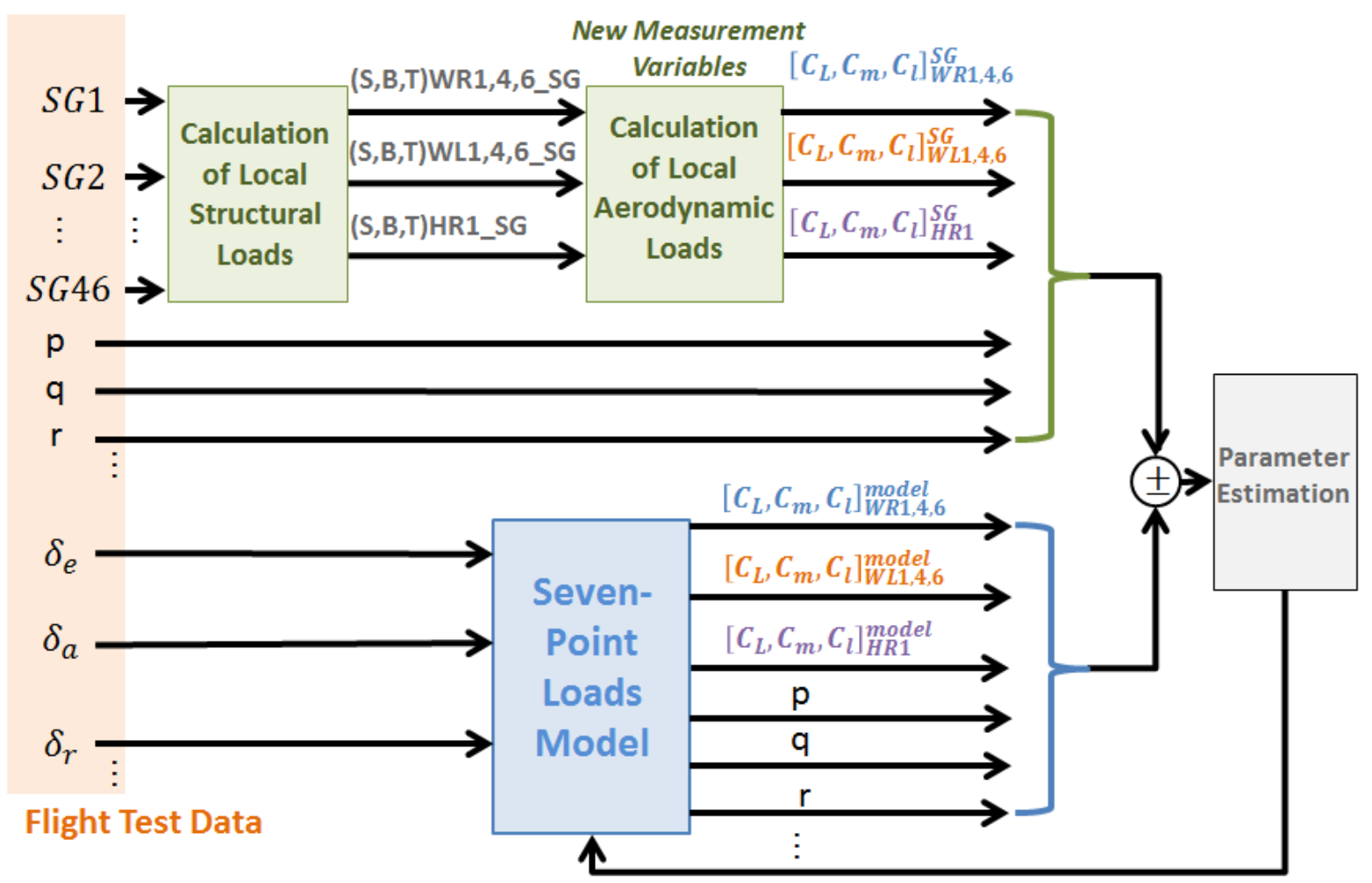

Figure 2. System-Identification approach of rigid-body multipoint loads model.

American Institute of Aeronautics and Astronautics 


\section{B. Discus-2c Flight Test for System-Identification}

The Discus- $2 \mathrm{c}^{25}$ is a single-seat high-performance sailplane manufactured by Schempp-Hirth Flugzeugbau GmbH (see Fig. 3). The test platform is equipped with special flight test instrumentation composed of: inertial and GPS sensors, control surface deflection sensors, five-hole probe nose boom, 46 strain gauge sensors and 15 threeaxis accelerometers at different aircraft locations. The 46 four-active-arm strain gauge (SG) bridges were calibrated $^{23,24}$ enabling the calculation of lift $\left(C_{L}\right)$, pitching $\left(C_{m}\right)$ and rolling $\left(C_{l}\right)$ moment coefficients at 7 load stations: 6 wing and 1 tail load stations (shown in Figs. 2 and 4: WR1, WL1, WR4, WL4, WR6, WL6 and HR1).

The flight test program took place from the airport of Braunschweig, Germany (EDVE) between July and October 2014. In about 20 flight hours, distributed over 22 flights, 396 test points were performed. For these flight tests, the sailplane was towed up to an altitude of 3,000 m. The flight envelope conditions encompassed three different airspeeds $(100 \mathrm{~km} / \mathrm{h}, 130 \mathrm{~km} / \mathrm{h}$ and $160 \mathrm{~km} / \mathrm{h})$. Additionally, deceleration maneuvers going from 1.50 to 1.05 of stall speed (approx. $90 \mathrm{~km} / \mathrm{h}$ to $65 \mathrm{~km} / \mathrm{h}$ ) were considered. The flight tests had four different objectives: parameter identification, multipoint flight loads modeling/monitoring considering rigid-body and aeroelastic degrees-of-freedom, quasi-steady stall modeling and validation.

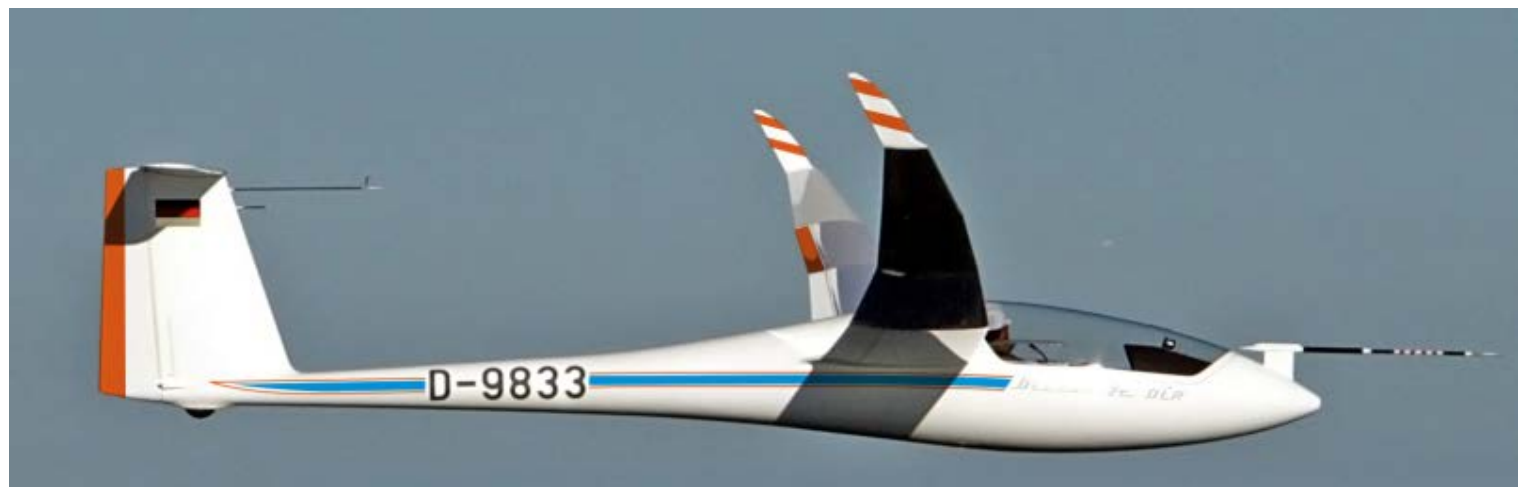

Figure 3: DLR Discus-2c Sailplane.

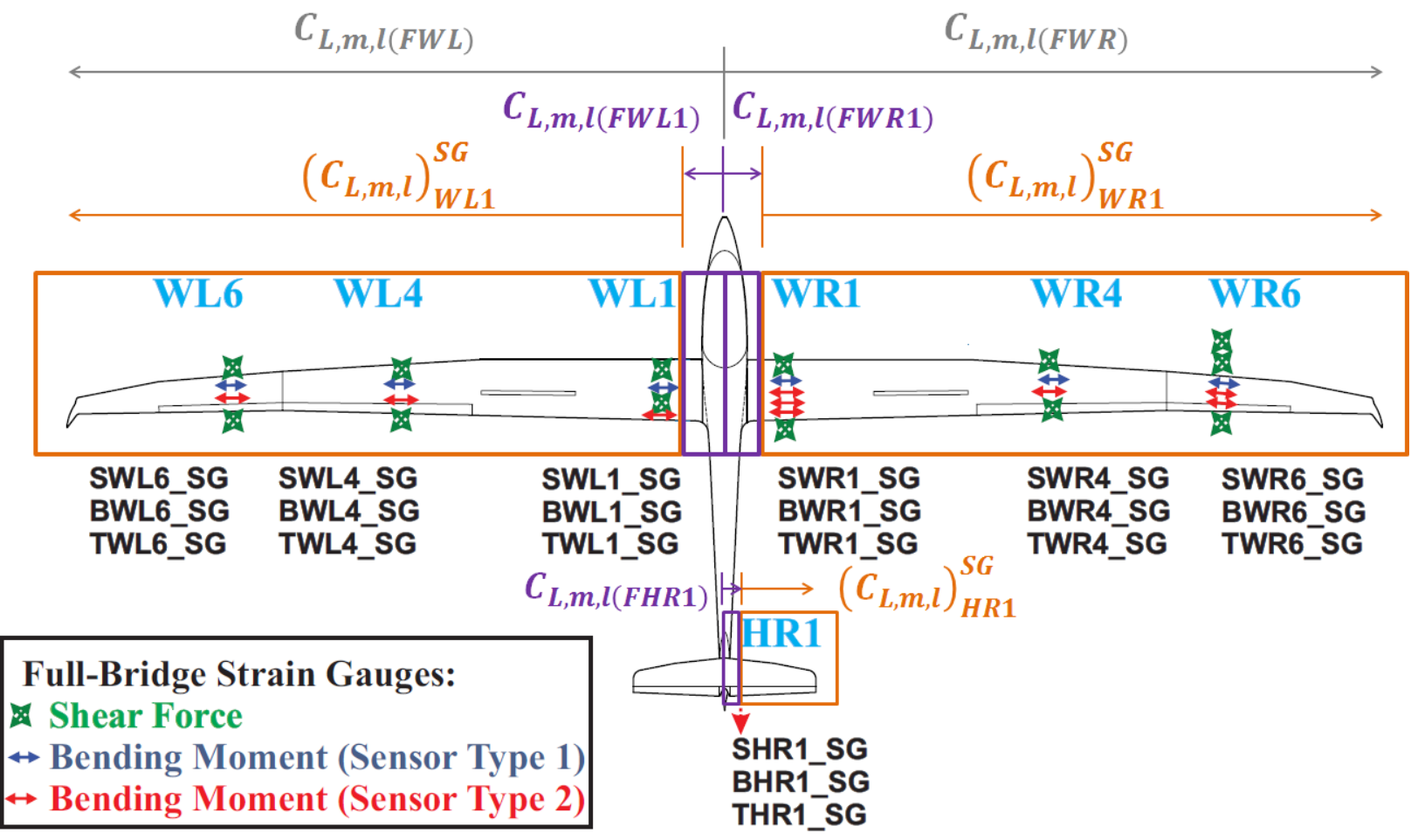

Figure 4. Structural and aerodynamic loads calculated from 46 strain gauge measurements ${ }^{23}$.

5

American Institute of Aeronautics and Astronautics 


\section{Model Formulation}

The scope of this paper is the modeling of the multipoint lift loads developed in the range of low frequency control inputs (i.e. the range of excitation of the rigid-body modes). A similar multipoint modeling approach was used for the pitching and rolling moment coefficients. A detailed description of the complete development of this multipoint loads model is given in Ref. 26.

\section{A. Equations of Motion}

The first step in the mathematical modeling of the rigid-body model is the consideration of the equations of motion. The translational equations of motion in the body-fixed axes system with the origin at the aircraft center of gravity (CG) are represented by the following equations ${ }^{22}$ :

$$
\begin{gathered}
\dot{u}=-q w+r v-g \sin \theta+X / m \\
\dot{v}=-r u+p w+g \cos \theta \sin \phi+Y / m \\
\dot{w}=-p v+q u+g \cos \theta \cos \phi+Z / m
\end{gathered}
$$

where $X, Y$ and $Z$ are the external forces or namely the aerodynamic forces, and $m$ is the aircraft mass.

The differential equations for the angular rates $p, q$ and $r$ are given by:

$$
\begin{gathered}
\dot{p}=\frac{p q\left[I_{X Z}\left(I_{Z Z}+I_{X X}-I_{Y Y}\right)\right]+q r\left[I_{Z Z}\left(I_{Y Y}-I_{Z Z}\right)-I_{X Z}^{2}\right]+\mathcal{L} I_{Z Z}+\mathcal{N} I_{X Z}}{I_{X X} I_{Z Z}-I_{X Z}^{2}} \\
\dot{q}=p r \frac{I_{Z Z}-I_{X X}}{I_{Y Y}}+\left(r^{2}-p^{2}\right) \frac{I_{X Z}}{I_{Y Y}}+\frac{M}{I_{Y Y}} \\
\dot{r}=\frac{p q\left[I_{X X}\left(I_{X X}-I_{Y Y}\right)+I_{X Z}^{2}\right]+q r\left[I_{X Z}\left(I_{Y Y}-I_{Z Z}-I_{X X}\right)\right]+\mathcal{L} I_{X Z}+\mathcal{N} I_{X X}}{I_{X X} I_{Z Z}-I_{X Z}^{2}}
\end{gathered}
$$

where $\mathcal{L}, M$ and $\mathcal{N}$ are the external moments. $I_{x x}, I_{y y}, I_{z z}, I_{x y}, I_{x z}$ and $I_{y z}$ are the moments of inertia.

This set of six equations represents the 6 degrees-of-freedom rigid-body dynamics, respectively, three translational and three rotational accelerations.

Additionally, the relationship between the Euler angles $\phi, \theta, \psi$ and the body-fixed angular speeds $p, q, r$ are given by the kinematical equations:

$$
\begin{gathered}
\dot{\phi}=p+q \sin \phi \tan \theta+r \cos \phi \tan \theta \\
\dot{\theta}=q \cos \phi-r \sin \phi \\
\dot{\psi}=q \sin \phi \sec \theta+r \cos \phi \sec \theta
\end{gathered}
$$

The last kinematic equation for the altitude is given by:

$$
\dot{h}=u \sin \theta-v \cos \theta \sin \phi-w \cos \theta \cos \phi
$$

\section{B. Rigid-Body Global Aerodynamic Loads Model}

This section presents the first step of the loads modeling approach proposed in this work. The rigid-body global aerodynamic loads model explained here (also called two-point model ${ }^{27}$ ) considers only the contributions of the wing and tail separately. The rigid-body global aerodynamic forces and moments [see Eqs. (1) and (2)] are given by:

$$
\begin{aligned}
& X=q_{\infty} S_{w} C_{X} \\
& Y=q_{\infty} S_{w} C_{Y} \\
& Z=q_{\infty} S_{w} C_{Z}
\end{aligned}
$$

$$
\begin{aligned}
\mathcal{L} & =q_{\infty} S_{w} b C_{l} \\
M & =q_{\infty} S_{w} c C_{m} \\
\mathcal{N} & =q_{\infty} S_{w} b C_{n}
\end{aligned}
$$


where $q_{\infty}$ is the dynamic pressure, $S_{w}$ is the wing reference area, $c$ is the mean aerodynamic chord, and $b$ is the wing span. The longitudinal and vertical force coefficients are determined from the contributions of the individual aircraft components, namely the fuselage/wings (FW) and fuselage/horizontal tail (FHT):

$$
\begin{aligned}
& C_{X}=C_{X(F W)}+C_{X(F H T)} \\
& C_{Z}=C_{Z(F W)}+C_{Z(F H T)}
\end{aligned}
$$

The FW force coefficients in the local aerodynamic system are transformed to the body axes reference system through the corresponding lift and drag components:

$$
\begin{gathered}
C_{X(F W)}=C_{L(F W)} \sin \alpha-C_{D(F W)} \cos \alpha \\
C_{Z(F W)}=-C_{L(F W)} \cos \alpha-C_{D(F W)} \sin \alpha
\end{gathered}
$$

Using the same approach, the FHT force coefficients are similarly expressed by:

$$
\begin{gathered}
C_{X(F H T)}=C_{L(F H T)} \sin \left(\alpha_{H}-i_{H}\right)-C_{D(F H T)} \cos \left(\alpha_{H}-i_{H}\right) \\
C_{Z(F H T)}=-C_{L(F H T)} \cos \left(\alpha_{H}-i_{H}\right)-C_{D(F H T)} \sin \left(\alpha_{H}-i_{H}\right)
\end{gathered}
$$

where $\alpha_{\mathrm{H}}$ represents the local angle of attack at the horizontal tail, which is modeled by the following expression ${ }^{28}$ :

$$
\alpha_{H}(t)=\alpha(t)-\varepsilon\left(t-\tau_{\varepsilon}\right)+i_{H}+\alpha_{d y n}(t)
$$

where $i_{H}$ is the tail incidence angle. $\alpha_{d y n}=\tan ^{-1}\left(q r_{H} / V\right)$ is the change of local angle of attack of the horizontal tail due to the aircraft rotation around the y-axis, and $r_{H}$ is the distance between the aircraft CG and the aerodynamic center (AC) of the horizontal tail. The term $\varepsilon$ represents the downwash angle and is modeled proportional to the wing angle $(\partial \varepsilon / \partial \alpha)$ delayed by the time $\tau_{\varepsilon}\left(=r_{H}^{*} / V\right)$ for the wing-generated vortex for reaching the horizontal tail $\mathrm{AC} ; r_{H}^{*}$ is the distance from the wing $\mathrm{AC}$ to the horizontal tail $\mathrm{AC}^{28}$ :

$$
\begin{aligned}
\varepsilon\left(t-\tau_{\varepsilon}\right) & =\varepsilon(t)-\left\{\varepsilon(t)-\varepsilon\left(t-\tau_{\varepsilon}\right)\right\} \\
& =\varepsilon_{0}+\frac{\partial \varepsilon}{\partial \alpha} \alpha(t)+\frac{\partial \varepsilon}{\partial X}[1-X(t)]-\left\{\varepsilon_{0}+\frac{\partial \varepsilon}{\partial \alpha} \alpha(t)+\frac{\partial \varepsilon}{\partial X}[1-X(t)]-\varepsilon\left(t-\tau_{\varepsilon}\right)\right\} \\
& =\frac{\partial \varepsilon}{\partial \alpha} \alpha(t)-\left\{\frac{\partial \varepsilon}{\partial \alpha} \alpha(t)-\varepsilon_{0}-\frac{\partial \varepsilon}{\partial \alpha} \alpha\left(t-\tau_{\varepsilon}\right)-\frac{\partial \varepsilon}{\partial X}\left[1-X\left(t-\tau_{\varepsilon}\right)\right]\right\} \\
& =\varepsilon_{0}+\frac{\partial \varepsilon}{\partial \alpha} \alpha(t)-\frac{\partial \varepsilon}{\partial \alpha} \dot{\alpha}(t) \frac{r_{H}^{*}}{V}+\frac{\partial \varepsilon}{\partial X}\left[1-X\left(t-\tau_{\varepsilon}\right)\right]
\end{aligned}
$$

where the last term represents the effect of the reduction of the wing lift curve slope at high angles of attack on the downwash angle acting on the horizontal tail. $\varepsilon_{0}$ represents the condition for wing lift is zero ${ }^{28}$; and $X$ is the instantaneous flow separation location along the chord on the wing upper surface.

For System-Identification the output error method ${ }^{22}$ in time domain is applied using the FITLAB ${ }^{29}$ software. Initially the conventional rigid-body two-point model described in this section was identified; the contributions of wing and horizontal tail were modeled separately. For this, the set of observation variables was composed by: basic airspeed $\left(V_{b}\right)$; static pressure $\left(p_{S}\right)$; angles of attack $(\alpha)$ and sideslip $(\beta)$; Euler angles $(\phi, \theta, \psi)$; angular rates $(p, q, r)$; and angular accelerations $(\dot{p}, \dot{q}, \dot{r})$.

\section{Rigid-Body Aerodynamic Loads Model Considering Local Loads Assessment: 3-Point Model}

The rigid-body multipoint aerodynamic loads model explained in sections III.C and III.D is an extension of the two-point model explained in the previous section which was considered the starting point for the next two steps: 1) Three-point model (separation of the right and left wing, and the tail); 2) Seven-point model (separation of right/left inner, mid, and outer wing parts and the tail). In the first step, considering this multipoint aerodynamic model structure, each wing is now accounted for separately and therefore the contributions from the complete wing 
principal longitudinal aerodynamic derivatives (e.g. $C_{L_{\alpha}}$ and $C_{L_{q}}$ ) need to be equally divided (i.e. right and left wing contributions). This is due to the assumption that the right and left wing have identical shapes, subject to the same longitudinal aerodynamic characteristics (i.e. equal longitudinal aerodynamic derivatives). The differences in the aerodynamic loads coefficients of each wing are considered to be due to the lateral-directional state and control variables (e.g. $\beta$ and $\delta_{a}$ ). For instance, these local differences can be observed in case of an aileron input resulting in an increase or decrease of the left/right wing lift which normally cancel each other, not changing the total aircraft lift. Therefore, the three-point model of the lift coefficient about the aircraft CG due to the fuselage/wing right (FWR), fuselage/wing left (FWL) and fuselage/horizontal tail (FHT) is modeled as:

$$
\begin{gathered}
C_{L(F W *)}(t)=C_{L_{0(F W *)}}+\frac{1}{2} C_{L_{\alpha(F W)}} C_{L_{Q S S F(F W)}}(t) \alpha(t)+\frac{1}{2} C_{L_{q(F W)}} \frac{q(t) c}{2 V(t)}+C_{L_{\beta^{2}(F W *)}} \beta^{2}(t) \\
+C_{L_{a}^{2}(F W *)} \delta_{a}^{2}(t)+\left[C_{L_{\delta_{a}^{s y m}} s y W_{(F W)}}+C_{L_{\alpha \delta_{a}} s y m_{(F W *)}} \alpha(t)\right] \delta_{a}^{s y m}(t) \\
C_{L(F H T)}(t)=\frac{S_{H}}{S_{w}}\left[C_{L_{\alpha(F H T)}} \alpha_{H}(t)+C_{L_{\delta e(F H T)}} \delta_{e}(t)\right] \cos \left(\alpha_{d y n}(t)-\varepsilon\left(t-\tau_{\varepsilon}\right)\right) \\
L(t)=q_{\infty}(t) S_{w}\left[C_{L(F W R)}(t)+C_{L(F W L)}(t)+C_{L(F H T)}(t)\right]
\end{gathered}
$$

where $S_{W}$ and $S_{H}$ are the wing and horizontal tail areas. The subscript $F W$ denotes the fuselage/wing combination; $F H T$ the fuselage/horizontal tail combination; and $F W *$ represents $F W R$ or $F W L$ as required. For example, $C_{L(F W R)}$ represents the identified lift coefficient due to the contribution fuselage/wing right combination. $L$ represents the modeled total lift force of the aircraft, which is discretized considering the three main lifting surfaces of the aircraft. $q_{\infty}$ is the dynamic pressure, $c$ the mean aerodynamic chord and $\delta_{e}$ the elevator deflection. $\delta_{a}\left(=\frac{\delta_{a}^{R}-\delta_{a}^{L}}{2}\right)$ and $\delta_{a}^{s y m}\left(=\frac{\delta_{a}^{R}+\delta_{a}^{L}}{2}\right)$ are the asymmetrical and symmetrical aileron deflections. The aerodynamic derivatives $C_{L_{\beta^{2}}}, C_{L_{\delta_{a}^{2}}}$, $C_{L_{a} \text { sym }}, C_{L_{\alpha \delta_{a}}^{\text {sym }}}$ account for cross-couplings between longitudinal and lateral-directional motion. The term $C_{L_{Q S S F}}$ represents the lift curve slope reduction for high angles of attack:

$$
C_{L_{Q S S F(F W)}}(t)=\left\{\frac{1+\sqrt{X(t)}}{2}\right\}^{2}
$$

where $X$ represents the instantaneous flow separation location along the chord on the wing upper surface:

$$
X(t)=\frac{1}{2}\left\{1-\tanh \left[a_{1}\left(\alpha(t)-\tau_{2} \dot{\alpha}(t)-\alpha^{*}\right)\right]\right\}
$$

where the flow separation point is modeled by the use of the airfoil static stall characteristics $\left(a_{1}\right)$, hysteresis time constant $\left(\tau_{2}\right)$, break point $\left(\alpha^{*}\right)$ and angle of attack $(\alpha)$ [see Ref. 22 for more details].

\section{Rigid-Body Aerodynamic Loads Model Considering Local Loads Assessment: 7-Point Model}

In the second step, the 3-point model is extended to a 7-point aerodynamic loads model, considering the loads measurements provided by the local aerodynamic load equations for the monitored load stations (namely, WR/L1, WR/L4, WR/L6 and HR1). This is achieved by further incorporating the aircraft component loads for each of the strain gauge loads measurement stations, as shown in Fig. 4.

It is important to consider that these aerodynamic load equations [e.g. $\left(C_{L, m, l}\right)_{W R 1}^{S G}$ ] calculate only the loads acting outboard of the monitored load station (see Fig. 4, which illustrates the cases for load stations WR1, WL1 and HR1). This is because a strain gauge bridge is in general not able to capture the load applied inboard of its load station ${ }^{17}$. Therefore, it is necessary to model the loads acting inboard of the considered load station. For example, the lift coefficient load equation at load station WR1 [i.e. $\left(C_{L}\right)_{W R 1}^{S G}$ ] does not consider the loads acting in the inboard position between this load station and the fuselage centerline [i.e. $C_{L(F W R 1)}$ ]; this is also the case for the loads acting on the fuselage, tail and left wing. For using the loads measurements as observation variables for each load station, the modeled total lift coefficient due to the fuselage/right wing (FWR) contribution [i.e. $C_{L(F W R)}-$ see Eq. (14)] has to be divided into two parts: the inboard and outboard component contributions. The inboard load has to be subtracted from the total load in order to obtain the outboard load, which is subsequently used to match with the 
loads measurements. These load components inboard of the monitored load stations have the following model structure for their rigid-body parts:

$$
\begin{aligned}
& C_{L(F W * *)}(\mathrm{t})=\mathrm{C}_{\mathrm{L}_{0(F W * *)}}+\mathrm{C}_{\mathrm{L}_{\alpha(F W * *)}} \mathrm{C}_{\mathrm{L}_{\mathrm{QSSF}(\mathrm{FW})}}(\mathrm{t}) \alpha(\mathrm{t})+\mathrm{C}_{\mathrm{L}_{\mathrm{q}(\mathrm{FW} *)}} \frac{\mathrm{q}(\mathrm{t}) \mathrm{c}}{2 \mathrm{~V}(\mathrm{t})}+\mathrm{C}_{\mathrm{L}_{\mathrm{r}(\mathrm{FW} * *)}} \frac{\mathrm{r}(\mathrm{t}) \mathrm{b}}{2 \mathrm{~V}(\mathrm{t})} \\
& +\mathrm{C}_{\mathrm{L}_{\delta \mathrm{a}(\mathrm{FW} * *)}} \delta_{\mathrm{a}}(\mathrm{t})+\mathrm{C}_{\mathrm{L}_{\dot{\mathrm{p}}(\mathrm{FW} * *)}} \frac{\dot{\mathrm{p}}(\mathrm{t}) b^{2}}{2 V^{2}(t)} \\
& 2 C_{L(F H R 1)}(\mathrm{t})=\mathrm{C}_{\mathrm{L}_{0}(\mathrm{FHR} 1)}+\mathrm{C}_{\mathrm{L}_{\alpha(\mathrm{FHR} 1)}} \alpha(\mathrm{t})+\mathrm{C}_{\mathrm{L}_{\mathrm{q}(\mathrm{FHR} 1)}} \frac{\mathrm{q}(\mathrm{t}) \mathrm{c}}{2 \mathrm{~V}(\mathrm{t})}+\mathrm{C}_{\mathrm{L}_{\dot{\alpha}(\mathrm{FHR} 1)}} \frac{\dot{\alpha}(\mathrm{t}) \mathrm{c}}{2 \mathrm{~V}(\mathrm{t})} \\
& +\mathrm{C}_{\mathrm{L}_{\delta \mathrm{e}(\mathrm{FHR} 1)}} \delta_{\mathrm{e}}(\mathrm{t})+\mathrm{C}_{\mathrm{L}_{\mathrm{p}(\mathrm{FHR} 1)}} \frac{\dot{\mathrm{p}}(\mathrm{t}) b^{2}}{2 V^{2}(t)}+\mathrm{C}_{\mathrm{L}_{\mathrm{r}(\mathrm{FHR} 1)}} \frac{\dot{\mathrm{r}}(\mathrm{t}) b^{2}}{2 V^{2}(t)} \\
& +\mathrm{C}_{\mathrm{L}_{\mathrm{X}(\mathrm{FHR} 1)}}\left[1-\mathrm{X}\left(\mathrm{t}-\tau_{\varepsilon}\right)\right]
\end{aligned}
$$

where the subscript $F W * *$ represents the loads contributions due to the aircraft component between the fuselage centerline (F) and each wing load station $W * *$ (see Fig. 4). $W * *$ can be $W R 1, W L 1, W R 4, W L 4, W R 6$ or $W L 6$ and the subsequent station numbering corresponds to the spanwise positions along the wing starting from that closest to the fuselage. Furthermore, the subscript FHR1 represents the loads contributions due to the aircraft component between the fuselage centerline $(F)$ and the horizontal tail load station HR1. The same explanations are applicable for the horizontal tail load coefficients [i.e. $C_{L(F H R 1)}$ ] regarding its monitored load station HR1. At the horizontal tail only one side has a load monitoring station (i.e. HR1), so that it is necessary to multiply the measured loads by two. In this context, the same procedure is applied for identification of the inboard loads [see Eq. (20)]. All parameters of $C_{L(F W * *)}$ and $C_{L(F H R 1)}$ (i.e. stability and control derivatives) were identified to enable the development of the rigidbody 7-point aerodynamic loads model.

Therefore, the aerodynamic load coefficients outboard of the load stations $W * *$ (or HR1) are finally modeled by the following expressions [considering Eqs. (19)-(20) and Eqs. (14)-(15)]:

$$
\begin{gathered}
\left(C_{L}\right)_{W * *}(t)=C_{L(F W *)}(t)-C_{L(F W * *)}(t) \\
2\left(C_{L}\right)_{H R 1}(t)=C_{L(F H T)}(t)-2 C_{L(F H R 1)}(t)
\end{gathered}
$$

where the subscript $F W * *$ means the loads contributions due to the aircraft component between the fuselage centerline $(F)$ and the wing load station $W * *$ (where $W * *=W R 1, W L 1, W R 4, W L 4, W R 6$ or $W L 6$ ). The subscript $F W *$ (either $F W R$ or $F W L$ ) denotes the loads acting between fuselage centerline (F) and the tip of the right (WR) or left (WL) wing. The subscript $W * *$ represents the loads acting at aircraft component outboard of the load station $W * *$. The same logic is applicable for the horizontal tail (HT) for the case considering its load station HR1.

The previous explanations show a different approach compared with the conventional rigid-body aircraft modeling, where longitudinal and lateral-directional motion are modeled in a decoupled manner, note that the right hand side of Eq. (21) consider not only the symmetric rigid-body motion [see Eqs. (14) and (19)]. In the present case, the contributions of the lateral-directional rigid-body degrees-of-freedom are also considered for modeling the local lift coefficients outboard of the wing load stations $W * *$. This is because the strain gauge measurements [i.e. $\left.\left(C_{L}\right)_{W * *}^{S G}\right]$ cannot separate the influences of longitudinal and lateral-directional degrees-of-freedom, as these sensors can only gather total and coupled influences of these two motions on the measured local loads. The same modeling approach was considered for the multipoint pitching and rolling moment coefficients [i.e. $\left(C_{m . l}\right)_{W * *}$ ] where the lateral-directional and longitudinal variables were taken into account allowing a proper equivalence with the correspondent measured local loads [i.e. $\left.\left(C_{m . l}\right)_{W * *}^{S G}\right]^{26}$. 


\section{Results and Analysis}

\section{A. System-Identification Results}

In summary, Eqs. (21) and (22) represent the rigid-body 7-point aerodynamic loads model. This model calculates the lift coefficients acting at the aircraft components outboard of the monitored load stations (i.e. WR/L1, WR/L4, WR/L6 and HR1), which are directly compared with the strain gauge measurements [i.e. 7 load equations $\left(C_{L}\right)_{W * *}^{S G}$ and $\left(C_{L}\right)_{H R 1}^{S G}$ - see Fig. 4]. Considering the approach outlined in Fig. 2, the previous set of observation variables was augmented by the addition of these 7 local loads measurements. Consequently, the parameters of the seven-point lift model were identified successfully. The identified parameter values for the modeling of the lift coefficients are presented in Table 1 [Eqs. (14) and (15)] and Table 2 [Eqs. (19) and (20)].

Table 1. Estimated parameters for the rigid-body three-point loads model.

\begin{tabular}{|c|c|c|c|c|c|}
\hline Parameter & $\begin{array}{c}\text { Value (relative } \\
\text { standard deviation) }\end{array}$ & Parameter & $\begin{array}{c}\text { Value (relative } \\
\text { standard deviation) }\end{array}$ & Parameter & $\begin{array}{c}\text { Value (relative } \\
\text { standard deviation) }\end{array}$ \\
\hline$C_{L_{0(F W R)}}$ & $1.42 \mathrm{e}-01(0.01 \%)$ & $C_{L_{\delta_{a}^{2}(F W L)}}$ & -1.46e-01 (1.35\%) & $\partial \varepsilon / \partial X, \mathrm{rad}$ & $3.01 \mathrm{e}-04(0.00 \%)$ \\
\hline$C_{L_{0(F W L)}}$ & $1.47 \mathrm{e}-01$ (0.01\%) & $C_{L_{a} \delta_{a}^{s y m}}$ & $6.14 \mathrm{e}-01(0.00 \%)$ & $C_{L_{\alpha(F H T)}}$ & $5.08 \mathrm{e}+00(0.00 \%)$ \\
\hline$C_{L_{\alpha(F W)}}$ & $6.16 \mathrm{e}+00(0.00 \%)$ & $C_{L_{a} \text { sym }_{(F W L)}}$ & $-1.68 \mathrm{e}-02(0.00 \%)$ & $C_{L_{\delta e(F H T)}}$ & $2.79 \mathrm{e}+00(0.00 \%)$ \\
\hline$C_{L_{q(F W)}}$ & $-1.63 e+01(0.00 \%)$ & $C_{L_{\alpha \delta_{a}^{s y m}}}$ & -8.07e-01 (0.00\%) & $a_{1}$ & $1.23 \mathrm{e}+01(0.02 \%)$ \\
\hline$C_{L_{\beta^{2}(F W R)}}$ & -1.93e-01 (0.03\%) & $C_{L_{\alpha \delta_{a}^{s y m}}}$ & $-3.72 \mathrm{e}+00(0.53 \%)$ & $\tau_{2}, s$ & $\begin{array}{c}8.67 \mathrm{e}+00 * \mathrm{c} / \mathrm{V} \\
(0.00 \%)\end{array}$ \\
\hline$C_{L_{\beta^{2}(F W L)}}$ & $-7.45 \mathrm{e}-02(0.01 \%)$ & $\varepsilon_{0}, \mathrm{rad}$ & $-6.15 \mathrm{e}-06$ (0.00\%) & $\alpha^{*}, \mathrm{rad}$ & $2.10 \mathrm{e}-01(0.00 \%)$ \\
\hline$C_{L_{\delta_{a}^{2}(F W R)}}$ & 8.73e-01 (0.00\%) & $\partial \varepsilon / \partial \alpha$ & 3.46e-01 (0.00\%) & & \\
\hline
\end{tabular}

Table 2. Estimated parameters of the inboard loads for the rigid-body seven-point loads model.

\begin{tabular}{|c|c|c|c|c|c|}
\hline Parameter & $\begin{array}{c}\text { Value (relative } \\
\text { standard deviation) }\end{array}$ & Parameter & $\begin{array}{c}\text { Value (relative } \\
\text { standard deviation) }\end{array}$ & Parameter & $\begin{array}{c}\text { Value (relative } \\
\text { standard deviation) }\end{array}$ \\
\hline $\mathrm{C}_{\mathrm{L}_{0(\mathrm{FWR} 1)}}$ & $1.36 \mathrm{e}-02$ (0.13\%) & $\mathrm{C}_{\mathrm{L}_{\mathrm{r}(\mathrm{FWR} 6)}}$ & 2.36e-02 (2.36\%) & $\mathrm{C}_{\mathrm{L}_{0(\mathrm{FWL} 6)}}$ & $1.32 \mathrm{e}-01(0.02 \%)$ \\
\hline $\mathrm{C}_{\mathrm{L}_{\alpha(\mathrm{FWR} 1)}}$ & 3.83e-01 (0.07\%) & $\mathrm{C}_{\mathrm{L}_{\delta(\mathrm{FWR})}}$ & 6.08e-02 (0.49\%) & $\mathrm{C}_{\mathrm{L}_{\alpha(\mathrm{FWL} 6)}}$ & $2.74 \mathrm{e}+00(0.01 \%)$ \\
\hline $\mathrm{C}_{\mathrm{L}_{\mathrm{q}(\mathrm{FWR} 1)}}$ & $-9.52 \mathrm{e}+00(0.14 \%)$ & $\mathrm{C}_{\mathrm{L}_{\dot{p}(\mathrm{FWR} 6)}}$ & 9.43e-02 (0.23\%) & $\mathrm{C}_{\mathrm{L}_{\mathrm{q}(\mathrm{FWL} 6)}}$ & $-7.62 \mathrm{e}+00(0.08 \%)$ \\
\hline $\mathrm{C}_{\mathrm{L}_{\mathrm{r}(\mathrm{FWR} 1)}}$ & 4.98e-02 (1.12\%) & $\mathrm{C}_{\mathrm{L}_{0(\mathrm{FWL} 1)}}$ & $2.22 \mathrm{e}-02(0.08 \%)$ & $\mathrm{C}_{\mathrm{L}_{\mathrm{r}(\mathrm{FWL})}}$ & $0(-)$ \\
\hline $\mathrm{C}_{\mathrm{L}_{\delta \mathrm{a}(\mathrm{FWR} 1)}}$ & $-1.96 \mathrm{e}-02$ (1.36\%) & $\mathrm{C}_{\mathrm{L}_{\alpha(\mathrm{FWL} 1)}}$ & 3.46e-01 (0.08\%) & $\mathrm{C}_{\mathrm{L}_{\delta \mathrm{a}(\mathrm{FWL})}}$ & $-4.08 \mathrm{e}-02(0.18 \%)$ \\
\hline $\mathrm{C}_{\mathrm{L}_{\dot{\mathrm{p}}(\mathrm{FWR} 1)}}$ & $2.42 \mathrm{e}-01(0.10 \%)$ & $\mathrm{C}_{\mathrm{L}_{\mathrm{q}(\mathrm{FWL} 1)}}$ & $-8.80 \mathrm{e}+00(0.16 \%)$ & $\mathrm{C}_{\mathrm{L}_{\dot{p}(\mathrm{FWL})}}$ & $-7.93 e-02(0.08 \%)$ \\
\hline $\mathrm{C}_{\mathrm{L}_{0(\mathrm{FWR} 4)}}$ & 9.18e-02 (0.01\%) & $\mathrm{C}_{\mathrm{L}_{\mathrm{r}(\mathrm{FWL} 1)}}$ & $-3.83 e-02(1.52 \%)$ & $\mathrm{C}_{\mathrm{L}_{0(\mathrm{FHR} 1)}}$ & $-2.09 \mathrm{e}-02(0.06 \%)$ \\
\hline $\mathrm{C}_{\mathrm{L}_{\alpha(\mathrm{FWR} 4)}}$ & $1.80 \mathrm{e}+00(0.01 \%)$ & $\mathrm{C}_{\mathrm{L}_{\delta \mathrm{a}(\mathrm{FWL} 1)}}$ & $4.95 e-02(0.56 \%)$ & $\mathrm{C}_{\mathrm{L}_{\alpha(\mathrm{FHR} 1)}}$ & $1.22 \mathrm{e}-01(0.11 \%)$ \\
\hline $\mathrm{C}_{\mathrm{L}_{\mathrm{q}(\mathrm{FWR} 4)}}$ & $-5.85 e+00(0.15 \%)$ & $\mathrm{C}_{\mathrm{L}_{\dot{\mathrm{p}}(\mathrm{FWL} 1)}}$ & $-2.41 \mathrm{e}-01(0.13 \%)$ & $\mathrm{C}_{\mathrm{L}_{\mathrm{q}(\mathrm{FHR} 1)}}$ & 6.92e-02 (8.59\%) \\
\hline $\mathrm{C}_{\mathrm{L}_{\mathrm{r}(\mathrm{FWR} 4)}}$ & 5.56e-03 (7.52\%) & $\mathrm{C}_{\mathrm{L}_{0(\mathrm{FWL} 4)}}$ & $1.04 \mathrm{e}-01(0.01 \%)$ & $\mathrm{C}_{\mathrm{L}_{\dot{\alpha}(\mathrm{FHR} 1)}}$ & $2.86 \mathrm{e}+00(0.34 \%)$ \\
\hline $\mathrm{C}_{\mathrm{L}_{\delta \mathrm{a}(\mathrm{FWR} 4)}}$ & -3.36e-03 (5.93\%) & $\mathrm{C}_{\mathrm{L}_{\alpha(\mathrm{FWL} 4)}}$ & $2.05 \mathrm{e}+00(0.01 \%)$ & $\mathrm{C}_{\mathrm{L}_{\delta \mathrm{e}(\mathrm{FHR} 1)}}$ & 7.02e-02 (0.17\%) \\
\hline $\mathrm{C}_{\mathrm{L}_{\dot{\mathbf{p}}(\mathrm{FWR} 4)}}$ & $1.85 \mathrm{e}-01(0.12 \%)$ & $\mathrm{C}_{\mathrm{L}_{\mathrm{q}(\mathrm{FWL} 4)}}$ & $-6.92 \mathrm{e}+00(0.11 \%)$ & $\mathrm{C}_{\mathrm{L}_{\dot{\mathbf{p}}(\mathrm{FHR} 1)}}$ & $1.25 \mathrm{e}-02(0.87 \%)$ \\
\hline $\mathrm{C}_{\mathrm{L}_{0(\mathrm{FWR} 6)}}$ & $1.26 \mathrm{e}-01$ (0.03\%) & $\mathrm{C}_{\mathrm{L}_{\mathrm{r}(\mathrm{FWL} 4)}}$ & $-1.70 \mathrm{e}-02(2.04 \%)$ & $\mathrm{C}_{\mathrm{L}_{\dot{\mathrm{r}}(\mathrm{FHR} 1)}}$ & $-1.20 \mathrm{e}-01(0.25 \%)$ \\
\hline $\mathrm{C}_{\mathrm{L}_{\alpha(\mathrm{FWR} \sigma)}}$ & $2.69 \mathrm{e}+00(0.01 \%)$ & $\mathrm{C}_{\mathrm{L}_{\delta \mathrm{a}(\mathrm{FWL} 4)}}$ & 1.07e-01 (0.15\%) & $\mathrm{C}_{\mathrm{L}_{\mathrm{X}(\mathrm{FHR} 1)}}$ & $0(-)$ \\
\hline $\mathrm{C}_{\mathrm{L}_{\mathrm{q}(\mathrm{FWR})}}$ & $-7.36 \mathrm{e}+00(0.14 \%)$ & $\mathrm{C}_{\mathrm{L}_{\dot{p}(\mathrm{FWL} 4)}}$ & -1.53e-01 (0.10\%) & & \\
\hline
\end{tabular}


In this work, the reliability of the identified parameters was assessed considering the threshold of $20 \%$ of their relative standard deviations (suggested by Tischler ${ }^{30}$ ). Considering high-quality flight test data (i.e. light turbulence, sufficient excitation, kinematically consistent), such parameters with a relative standard deviation greater than $20 \%$ were removed from the model (i.e. its value was set as zero - see Table 2) and the identification was repeated.

In summary, the identified multipoint loads model is able to predict local aerodynamic loads independently of direct load or strain measurements. This means that aerodynamic loads can be monitored at different positions of the aircraft in real-time using standard aircraft sensors.

\section{B. Analysis of the Local Loads}

In this section, the System-Identification results are evaluated considering some flight test maneuvers. For this purpose, the model outputs (red lines) are compared with the measured flight data (blue lines, for clarity black lines represent left aileron deflections). Maneuvers with longitudinal and lateral control inputs were analyzed. In these figures the identified local lift coefficients [red lines: $\left(\mathrm{C}_{\mathrm{L}}\right)_{\mathrm{WR} 1},\left(\mathrm{C}_{\mathrm{L}}\right)_{\mathrm{WL} 1},\left(\mathrm{C}_{\mathrm{L}}\right)_{\mathrm{WR} 4},\left(\mathrm{C}_{\mathrm{L}}\right)_{\mathrm{WL} 4},\left(\mathrm{C}_{\mathrm{L}}\right)_{\mathrm{WR} 6},\left(\mathrm{C}_{\mathrm{L}}\right)_{\mathrm{WL} 6}$ and $\left(\mathrm{C}_{\mathrm{L}}\right)_{\mathrm{HR} 1}$ ] acting at right $(\mathrm{WR})$ and left $(\mathrm{WL})$ wing, and right tail $(\mathrm{HR})$ are compared with the correspondent measured lift coefficients [blue lines: $\left(\mathrm{C}_{\mathrm{L}}\right)_{\mathrm{WR} 1}^{\mathrm{SG}},\left(\mathrm{C}_{\mathrm{L}}\right)_{\mathrm{WL} 1}^{\mathrm{SG}},\left(\mathrm{C}_{\mathrm{L}}\right)_{\mathrm{WR} 4}^{\mathrm{SG}},\left(\mathrm{C}_{\mathrm{L}}\right)_{\mathrm{WL} 4}^{\mathrm{SG}},\left(\mathrm{C}_{\mathrm{L}}\right)_{\mathrm{WR} 6}^{\mathrm{SG}}\left(\mathrm{C}_{\mathrm{L}}\right)_{\mathrm{WL} 6}^{\mathrm{SG}}$ and $\left(\mathrm{C}_{\mathrm{L}}\right)_{\mathrm{HR} 1}^{\mathrm{SG}}$.

Figure 5 shows a sequence of two 3-2-1-1 elevator multistep inputs, where the resultant effects on the local loads at wings and horizontal tail are evident. This type of input was used for covering a wideband of frequencies expected for the rigid-body modes. These plots show that the predicted aircraft loads are representative of the actual loads measured in flight for all monitored load stations.

Another maneuver used for System-Identification was a stall approach combined with a sequence of elevator doublets (shown in Fig. 6). This provides flight data that cover a large range of angle of attack (AOA), pitch rate and elevator deflection ${ }^{31}$. This maneuver was important to address a large portion of the independent variables that are influent for the development of a comprehensive loads model. It can be observed that the identified multipoint loads model presents a good agreement with the measured local loads along the entire AOA range. Additionally, these results show the efficacy of the quasi-steady stall model used to account for the wing lift-curve slope reduction at high AOA. Without considering this model, the predicted loads at this region were overestimated and did not match with the strain gauge measurements.

The bank-to-bank roll maneuver is useful for parameter estimation, allowing the determination of aerodynamic couplings between roll and yaw axes ${ }^{22}$. Figure 7 shows a bank-to-bank roll combined with elevator doublets, which allows separating pitch and AOA rate components of longitudinal motion ${ }^{22}$. This maneuver demonstrates the influence of lateral motion on the longitudinal loads. It can be noticed that the local lift coefficients at the six wing load stations are influenced by the aileron inputs (see the load peaks around $2.0 \mathrm{~s}$ and $13.5 \mathrm{~s}$ ). Additionally, comparing measured and predicted state variables and local lift coefficients, the accurate modeling of aircraft behavior can be verified along different bank angle levels and elevator excitations.

For a better understanding of the influence of the coupling between longitudinal and lateral-directional degreesof-freedom on the local loads, several types of flight maneuvers were applied to the System-Identification process. One example is the 3-2-1-1 aileron multistep input shown in Fig. 8. It is noticeable that the peaks of the local spanwise lift coefficient along the wing relate to the aileron excitations. Furthermore, it is possible to observe the modeling of the loads reacted by the horizontal tailplane due to the aircraft lateral motion.

Figure 9 shows a longitudinal pushover-pullup maneuver (called roller-coaster), which is a low-frequency longitudinal doublet. This maneuver allows the characterization of the lift and drag performance over a relatively large AOA range $\mathrm{e}^{22,31}$. The match between the model outputs and the measured flight data is satisfactory, with good agreement between the measured and the predicted local loads during a wide range of AOA. As an exception, the lift coefficient at load station HR1 presents a mismatch in the high AOA region. As explained in Ref. 26, this can be

due to the impossibility of identifying the parameter $\mathrm{C}_{\mathrm{Lx}(\mathrm{FHR} 1)}{ }^{\dagger}$ and due to inadequate compensation of temperature effects (causing measurement drifts in long maneuvers). In other words, this identification issue can occur due to insufficient information content provided by the small HT loads, which are measured by a limited number of strain gauge sensors. This example shows again the importance of the quasi-steady stall modeling allowing accurate load predictions at high AOA.

\footnotetext{
${ }^{\dagger}$ Modeling of the effects of wing lift curve slope reduction on the lift at the horizontal tailplane.
} 

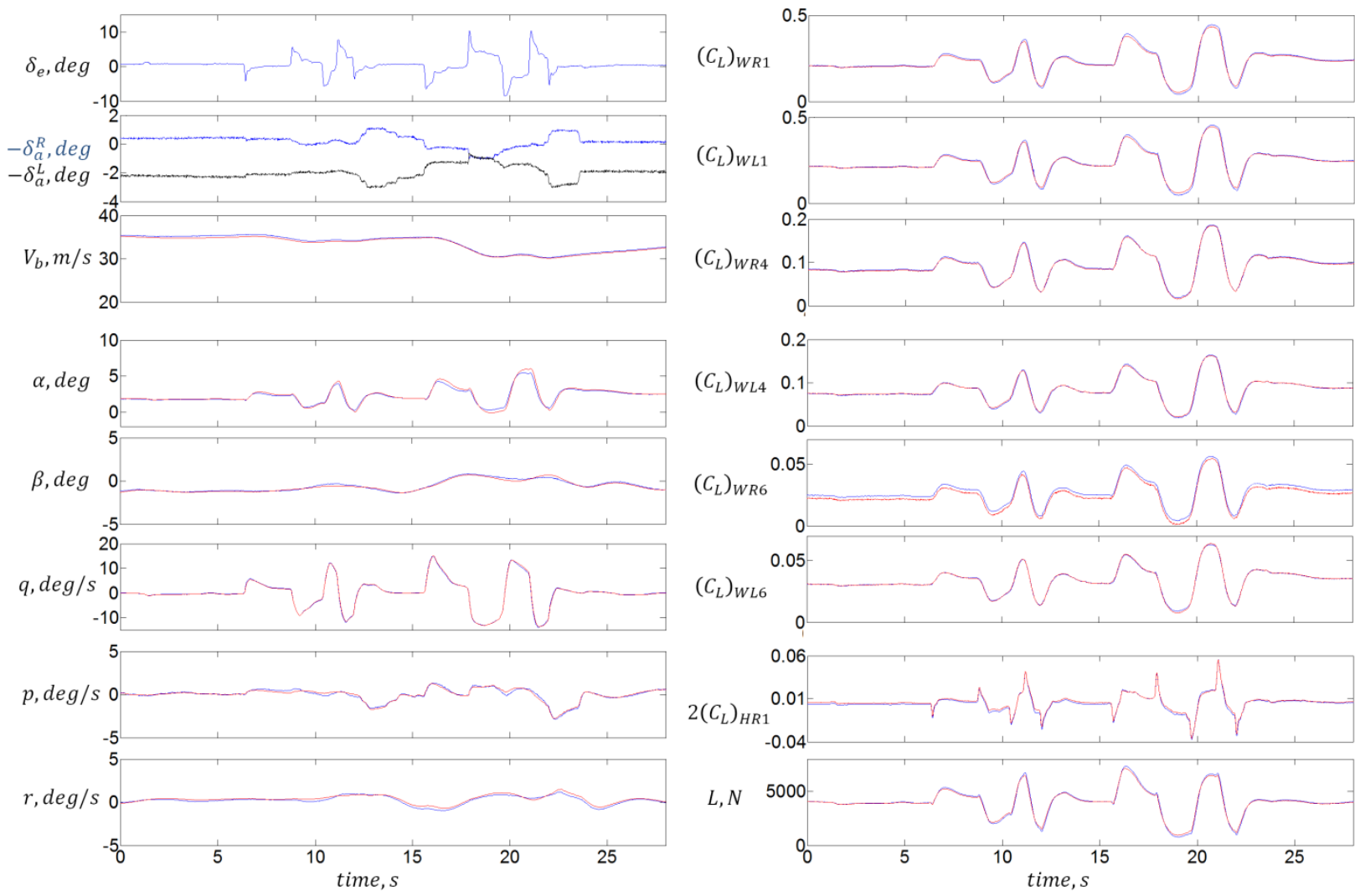

Figure 5. Comparison Measurement - Model: Sequence of two 3-2-1-1 elevator multistep inputs.
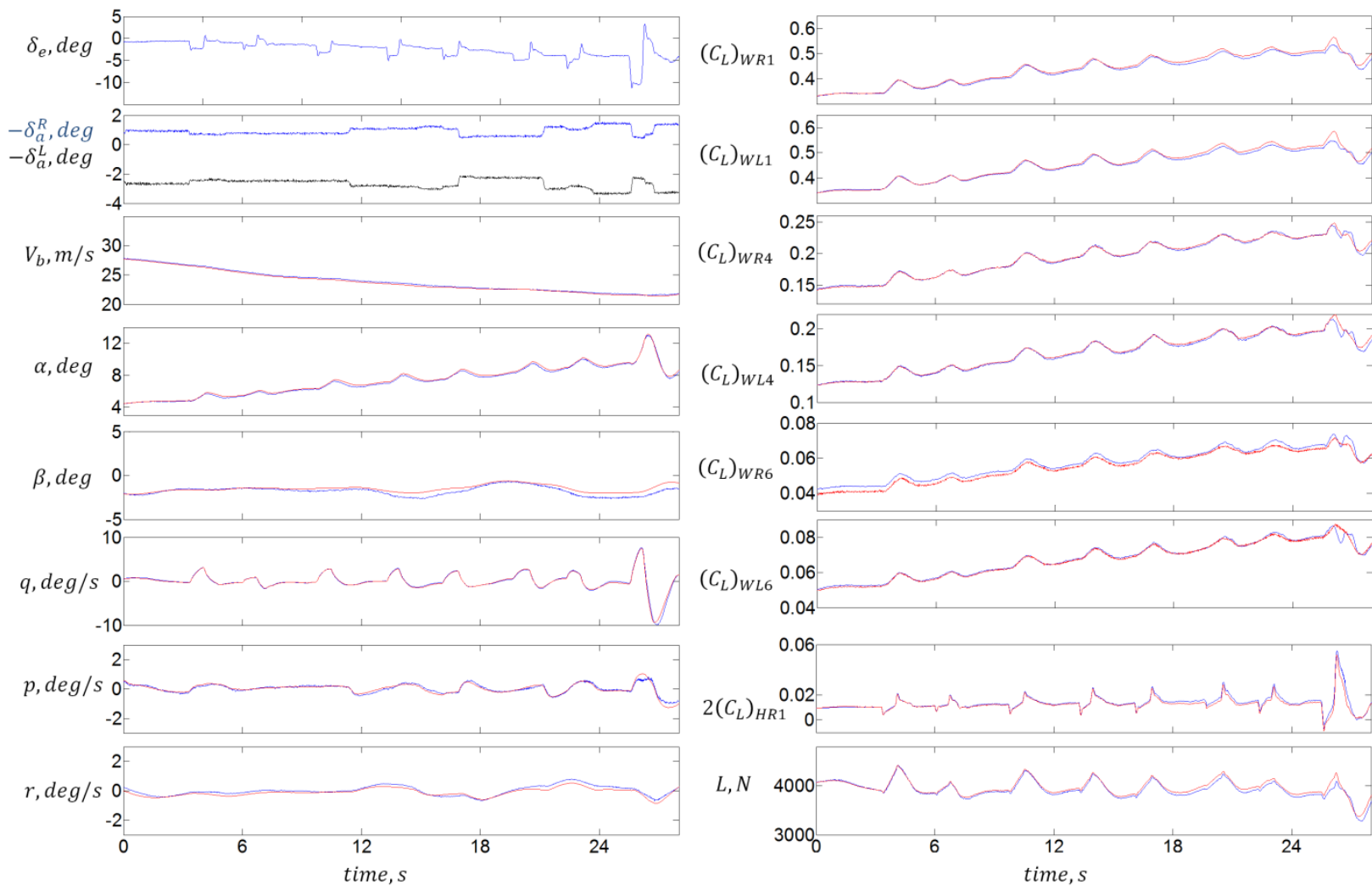

Figure 6. Comparison Measurement - Model: Stall approach combined with elevator doublets.

12

American Institute of Aeronautics and Astronautics 


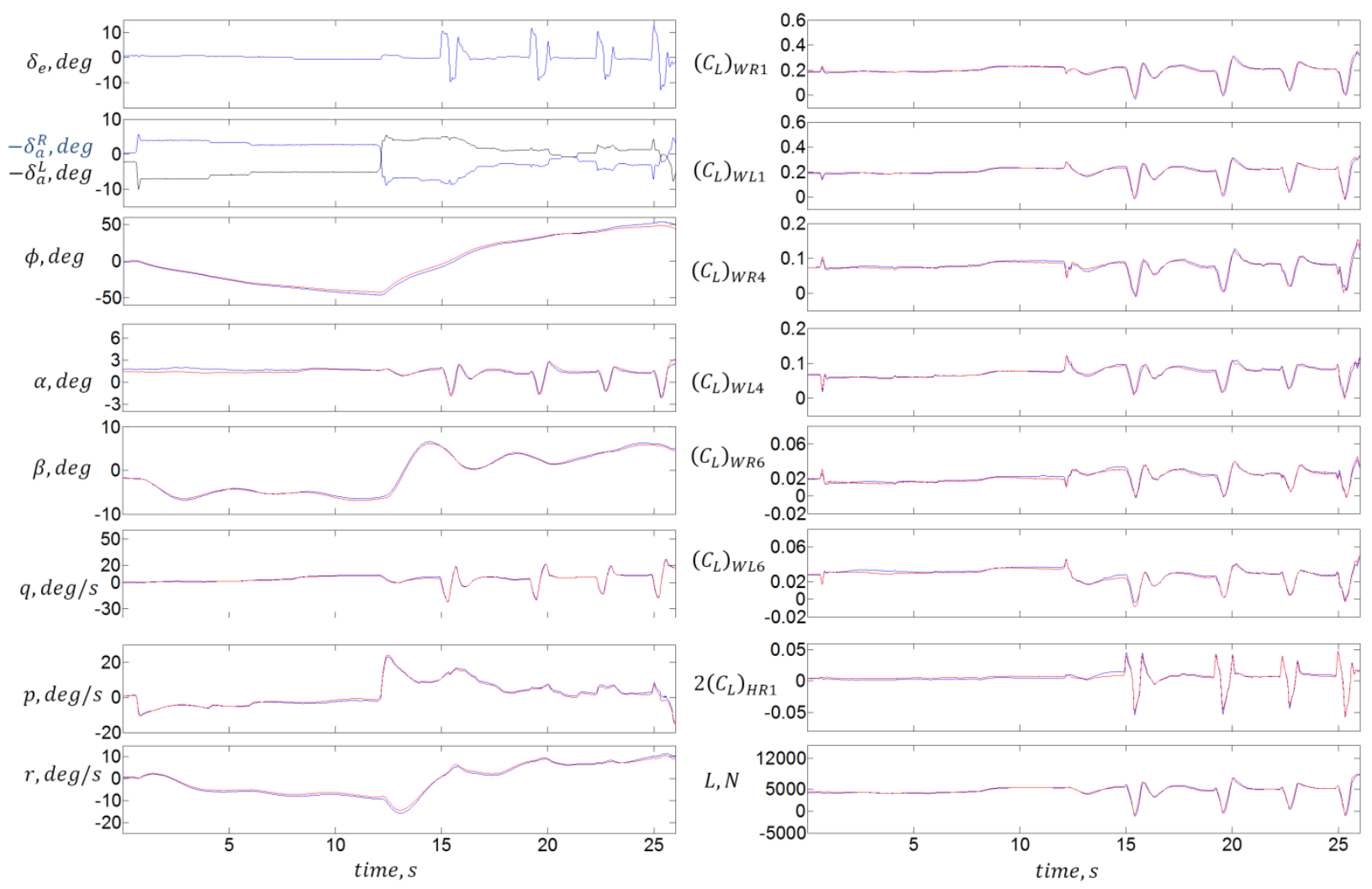

Figure 7. Comparison Measurement - Model: Bank-to-bank roll combined with elevator doublets.
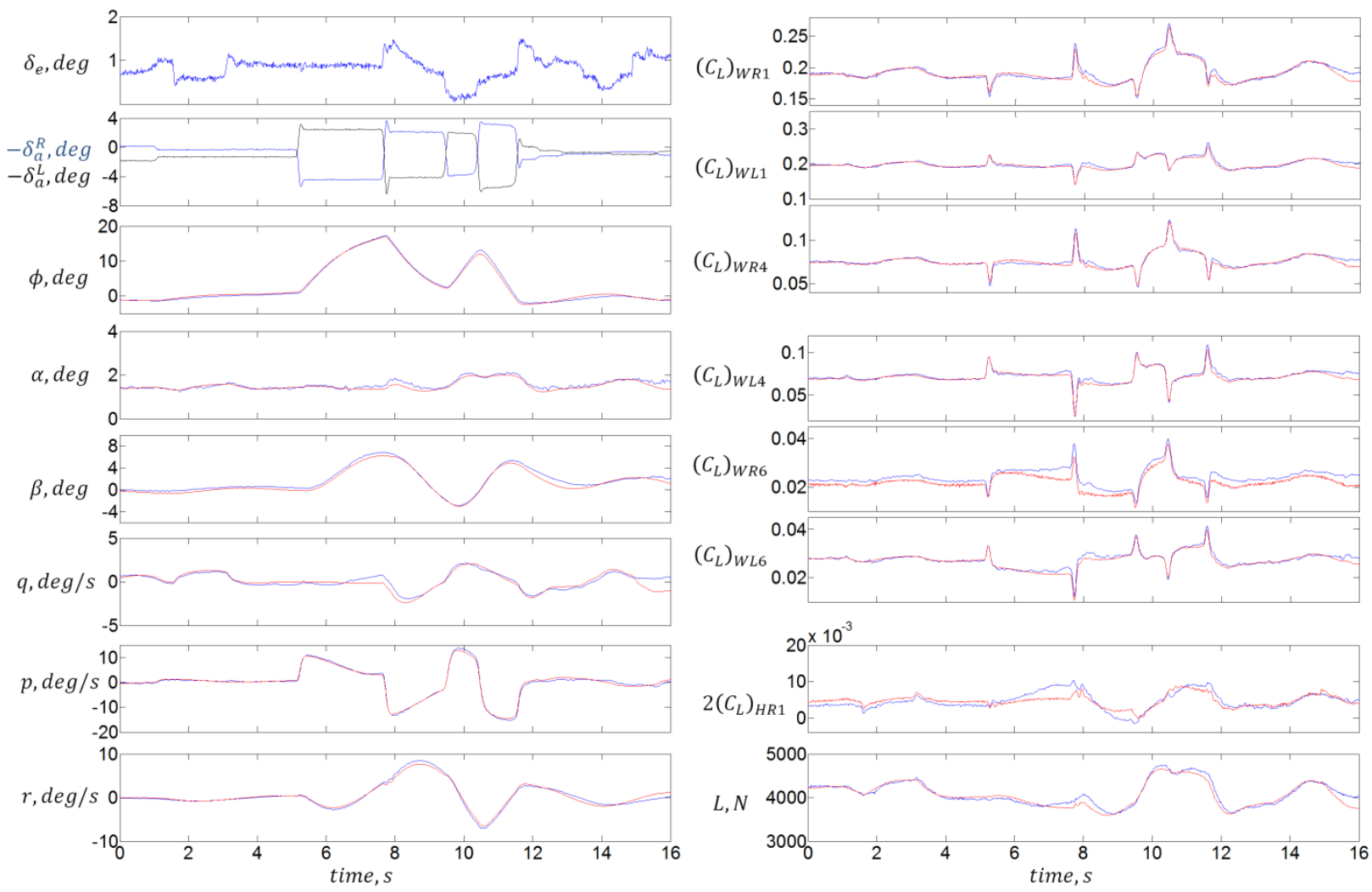

Figure 8. Comparison Measurement - Model: 3-2-1-1 aileron multistep inputs.

13

American Institute of Aeronautics and Astronautics 

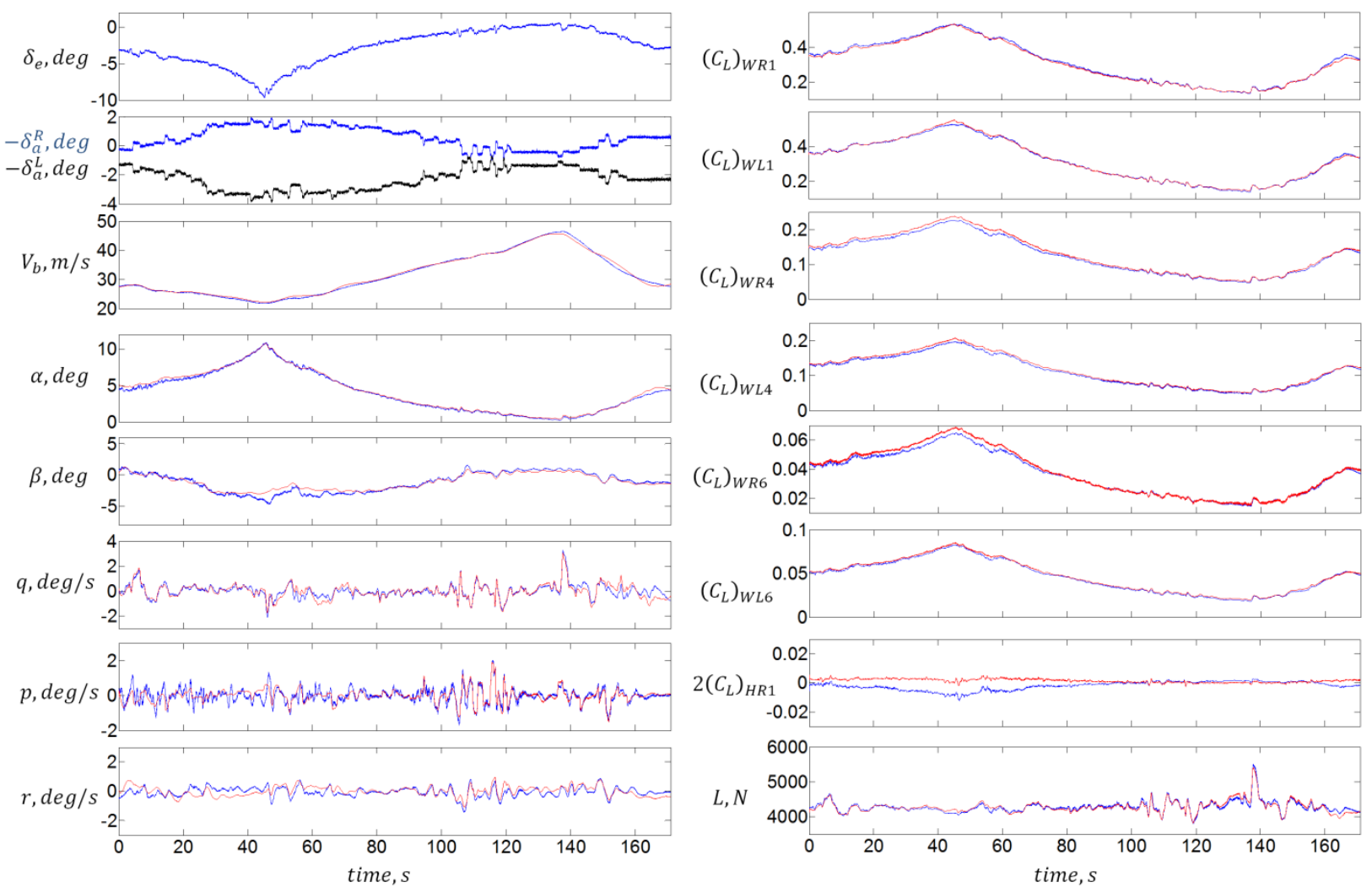

Figure 9. Comparison Measurement - Model: Pushover-pullup.
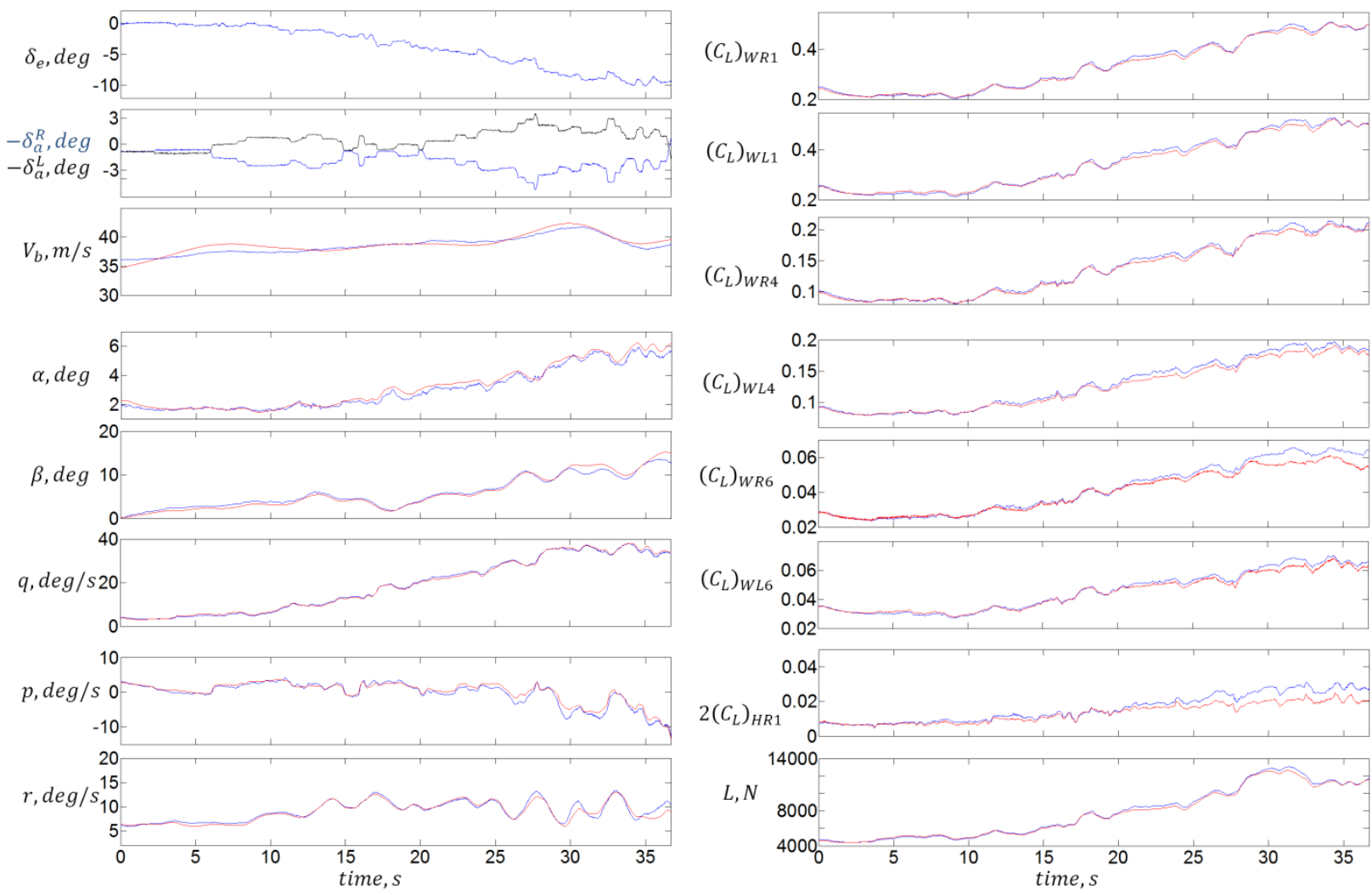

Figure 10. Comparison Measurement - Model: Wind-up turn.

American Institute of Aeronautics and Astronautics 
The wind-up turn maneuver was used for flight loads modeling and system identification. The wind-up turn had the purpose of aiding the determination of drag and lift coefficients at different AOA and increasing normal load factors for constant airspeed ${ }^{22,31}$. Figure 10 shows a wind-up turn, where a normal acceleration of $3.4 \mathrm{~g}$ was reached at the inertial measurement unit (demonstrated by the maximum lift force of about $13000 \mathrm{~N}$ ). During the large range of AOA and normal load factors, the predicted local lift coefficients show a satisfactory matching with the corresponding measured local loads. Small mismatches occur for the local lift coefficients at the load stations WR6 and HR1, probably due to the small level of load changes at these smaller aircraft parts. The observed model deficiencies arise from practical limitations to excite sufficiently each influent variable and having enough sensors to gather accurately this information along the frequency range of interest ${ }^{26}$.

\section{Summary}

In general, there is a good agreement between the measured and predicted seven-point lift coefficients, showing the accuracy of the developed multipoint loads model. Some mismatches were observed, mainly, at the lift coefficients developed at load stations WR6 and HR1. As explained in Ref. 26 concerning sources of inaccuracies, contributing factors for these issues are probably the lower number of strain sensors available at these load stations and the residual errors on the compensation of temperature effects of the strain sensors at the horizontal tailplane. Moreover, the good matches between the other model outputs (e.g. state variables and total lift) and correspondent measured flight data ratify the consistency of the identified rigid-body multipoint loads model. Therefore, the additional observation variables (represented by the local loads measurements) proved valuable efficacy for the identification of the several parameters that compose this multipoint loads model. For future development, the identified rigid-body seven-point loads model shows promising application for aircraft real-time structural health monitoring using exclusively the standard aircraft sensors.

\section{Conclusion}

This research has addressed the problem of loads acting on several aircraft components, focusing on how to model them through a straightforward approach. Loads are the results of the aircraft structural behavior and the interaction between the complex aircraft motion and the aerodynamic flow. Moreover, these loads are characterized by a complex interaction of shear force, bending moment and torque acting throughout the aircraft structure. These issues are critical for the aeronautical industry (e.g. the aircraft load envelope should satisfy the certification requirements) as well as for the aircraft operators (e.g. a cost-effective loads monitoring approach). Therefore, solutions that address this research field with practical applications are highly valuable.

To achieve this objective, flight tests were performed using a high-performance sailplane equipped with special flight test instrumentation. Several sensors, accelerometers and strain sensors were installed over the aircraft structure in order to gather the necessary flight data. For obtaining the observation variables necessary for the multipoint loads modeling, it was mandatory to have available local loads information. This was achieved by the calibration of a host of strain sensors. Subsequently, the additional observation variables were provided by the local aerodynamic load equations, which rely on the calibrated strain sensors.

The objective of this paper was to demonstrate the proposed multipoint loads modeling approach for the case of the lift coefficients at seven monitored load stations. The postulated model structure provides the ability to satisfactorily perform multipoint loads modeling. Moreover, the good agreements between the measured local loads from the strain gauges and the predicted loads from the identified rigid-body model proved the efficacy of these additional observations. The contribution of this work was to develop a multipoint aerodynamic loads model for supporting future real-time SHM applications. As a result, the approach presented in this paper has the novelty of extending the conventional global System-Identification approach, in order to enable the simulation of local loads in real time. Future work will address the modeling of the effects of the aircraft structural dynamics (i.e. structural flexibility) on this multipoint loads model.

\section{Acknowledgments}

The author would like to thank the Institute of Flight Systems at DLR (German Aerospace Center) and the Brazilian Air Force (BAF) for the technical and financial supports regarding this project of multipoint loads model for flexible aircraft health monitoring in real time, which uses the DLR Discus-2c sailplane as test platform.

The contributions of Kai Rohde-Brandenburger and Johannes Anton for the flight test performance are gratefully acknowledged. A special acknowledgment goes to Per Ohme, Christian Raab and Piotr Lichota for their valuable technical discussions. The author is also grateful to Christian Gall and Pierre-Daniel Jameson for supporting the several ground and flight tests. 


\section{References}

${ }^{1}$ Wright, J. R., Cooper, J. E., Introduction to Aircraft Aeroelasticity and Loads, John Wiley \& Sons, Chichester, England, 2007.

${ }^{2}$ Boller, C., Buderath, M., "Fatigue in Aerostructures - Where Structural Health Monitoring can Contribute to a Complex Subject,” Philosophical Transactions of the Royal Society of London A: Mathematical, Physical and Engineering Sciences, Vol. 365, No. 1851, pp. 561-587, 2007.

${ }^{3}$ Staszewski, W., Boller, C., Tomlinson, G. R., Health Monitoring of Aerospace Structures: Smart Sensor Technologies and Signal Processing, John Wiley \& Sons, Chichester, England, 2004.

${ }^{4}$ Günther, G., "Loads Monitoring and HUMS,” Aging Aircraft Fleets: Structural and Other Subsystem Aspects, NATO RTOEN-015 AC/323 (AVT-053) TP/33, 2001.

${ }^{5}$ Reijerkerk, M. J., “Aeroelastic Model Identification of Winglet Loads from Flight Test Data,” Ph.D. Dissertation, TU Delft, Delft University of Technology, 2008.

${ }^{6}$ Ladda, V., Meyer, H.-J., “The Operational Loads Monitoring System OLMS,” AGARD Conference Proceedings 506 (AGARD-CP-506): Fatigue Management, Paper 15, 1991.

${ }^{7}$ Nicholas, O. P., "Tests on a Hunter F.2 of Two Strain Gauge Methods for Measuring Tailplane Loads in Flight, with some Loads Measured in Level Flight, Pitch-ups and Transonic Dives,” CP-754, British Aeronautical Research Council, 1964.

${ }^{8}$ Aiken, W. S., Jr., "Flight Determination of Wing and Tail Loads on a Fighter-Type Airplane by Means of Strain-Gage Measurements,” NASA Technical Note No. 1729, 1948.

${ }^{9}$ Aiken, W. S., Jr., Howard, D. A., “A Comparison of Wing Loads Measured in Flight on a Fighter-Type Airplane by StrainGage and Pressure-Distribution Methods,” NASA Technical Note No. 1967, 1949.

${ }^{10}$ Hovell, P. B., Webber, D. A., Roberts, T. A., “The Use of Calibrated Strain Gauges for Flight Load Determination,” CP1041, British Aeronautical Research Council, 1969.

${ }^{11}$ Reymer, P., "Validation of the FEM Model of the Mi-24 Tail Boom and Vertical Stabilizer,” Journal of KONES Powertrain and Transport, Vol. 18, No. 2, pp. 369-376, 2011

${ }^{12}$ Hovell, P. B., Webber, D. A., Roberts, T. A., “The Interpretation of Strain Measurements for Flight Load Determination,” CP-839, British Aeronautical Research Council, 1964.

${ }^{13}$ Emmons, M. C., Karnani, S., Trono, S., Mohanchandra, K. P., Richards, W. L., Carman, G. P., "Strain Measurement Validation of Embedded Fiber Bragg Gratings,” International Journal of Optomechatronics, Vol. 4, No. 1, pp. 22-33, 2010.

${ }^{14}$ Schmidt, H.-J., Schmidt-Brandecker, B., "Fatigue and Damage Tolerance Behaviour of Advanced Structures in Aeronautics.”

${ }^{15}$ Trutzel, M. N., Wauer, K., Betz, D., Staudigel, L., Krumpholz, O., Muehlmann, H.-C., Muellert, T., Gleine, W., “Smart Sensing of Aviation Structures with Fibre-optic Bragg Grating Sensors,” Sensory Phenomena and Measurement Instrumentation for Smart Structures and Materials, International Society for Optics and Photonics, SPIE Vol. 3986, pp. 134-143, 2000.

${ }^{16}$ Henrichfreise, H., Bensch, L., Jusseit, J., Merz, L., Gojny, M., "Estimation of Gusts and Structural Loads for Commercial Aircraft,” International Forum on Aeroelasticity and Structural Dynamics (IFASD), Seattle, USA, 2009.

${ }^{17}$ Skopinski, T. H., Aiken, W. S., Jr., Huston, W. B., "Calibration of Strain-Gage Installations in Aircraft Structures for the Measurement of Flight Loads,” NACA Report 1178, 1954.

${ }^{18}$ Lokos, W. A., Olney, C. D., Chen, T., Crawford, N. D., Stauf, R., Reichenbach, E. Y., "Strain-Gage Loads Calibration Testing of the Active Aeroelastic Wing F/A-18 Airplane,” AIAA Aerodynamic Measurement Technology and Ground Testing Conference, paper AIAA 2002-2926, Saint Louis, MO, USA, 2002.

${ }^{19}$ Lokos, W. A., Stauf, R., "Strain-Gage Loads Calibration Parametric Study," NASA Technical Memorandum 212853 (NASA/TM-2004-212853), 2004.

${ }^{20}$ Nelson II, S. A., “Strain Gage Selection in Loads Equations Using a Genetic Algorithm,” NASA Contractor Report 4597 (NASA CR-4597), 1994.

${ }^{21}$ Jenkins, J. M., DeAngelis, V. M., “A Summary of Numerous Strain-Gage Load Calibrations on Aircraft Wings and Tails in a Technology Format,” NASA Technical Memorandum 4804 (NASA TM-4804), 1997.

${ }^{22}$ Jategaonkar, R. V., Flight Vehicle System Identification: A Time Domain Methodology, Progress in Astronautics and Aeronautics, Volume 216, American Institute of Aeronautics and Astronautics, Reston, VA, USA, 2006.

${ }^{23}$ Preisighe Viana, M. V., "Sensor Calibration for Calculation of Loads on a Flexible Aircraft," International Forum on Aeroelasticity and Structural Dynamics (IFASD), paper IFASD-2015-042, Saint Petersburg, Russia, 2015.

${ }^{24}$ Preisighe Viana, M. V., "Sensor Calibration for Calculation of Loads on the DLR Discus-2c Sailplane," DLR internal report IB 111-2015/21, Braunschweig, Germany, 2015.

${ }^{25}$ Schempp-Hirth Flugzeugbau GmbH, “Flughandbuch für das Segelflugzeug Discus-2c,” Kirchheim unter Teck, Germany, 2005 (in German).

${ }^{26}$ Preisighe Viana, M. V., “Multipoint Loads Model for Flexible Aircraft Health Monitoring in Real Time,” Ph.D. Dissertation, Technische Universität Braunschweig, Fakultät für Maschinenbau, Braunschweig, Germany (to be published).

${ }^{27}$ Mönnich, W., "Ein 2-Punkt-Aerodynamikmodell für die Identifizierung," Symposium 'Systemidentifikation in der Fahrzeugdynamik,' DFVLR Mitteilung 87-22, Paper No. 3.1, Braunschweig, Germany, 1987 (in German).

${ }^{28}$ Schmidt, D. K., Modern Flight Dynamics, $1^{\text {st }}$ ed., McGraw-Hill, New York, USA, 2012.

${ }^{29}$ Seher-Weiss, S., “User's Guide - FITLAB - Parameter Estimation Using MATLAB," Version 2.3, DLR - Institute of Flight Systems, IB-111-2014/07, Braunschweig, Germany, 2014. 
${ }^{30}$ Tischler, M. B., Remple, R. K., Aircraft and Rotorcraft System Identification: Engineering Methods with Flight Test Examples, AIAA Education Series, AIAA, Reston, VA, USA, 2006.

${ }^{31}$ Klein, V., Morelli, E. A., Aircraft System Identification: Theory and Practice, AIAA Education Series, AIAA, Reston, VA, USA, 2006. 